\title{
Chlorpromazine therapy, and associated acute disturbances of cardiac rhythm
}

\author{
S. J. Aherwadkar, Mutia Canan Efendigil, and N. Coulshed \\ From the Liverpool Regional Cardiac Centre, Sefton General Hospital, Liverpool
}

\begin{abstract}
A patient is presented who developed transient complete heart block, with right bundle-branch block and left anterior hemiblock as a result of prolonged but irregular chlorpromazine therapy. Withdrawal of the drug resulted in reversion tó normal rhythm, but reintroduction caused other rhythm disturbances to appear.
\end{abstract}

Both clinical observation and experimental animal studies have shown that chlorpromazine can produce disturbance of normal cardiac rhythm. Atrioventricular and intraventricular conduction defects have been demonstrated, as have various types of tachyarrhythmias, but there have been no reports of complete heart block, associated with the previous presence of right bundle-branch block and left anterior hemiblock.

We would like to report such a case, where the patient also showed ventricular tachycardia provoked by chlorpromazine.

\section{Case report}

The patient, a 30-year-old woman, had been treated with chlorpromazine over a period of ro years, in an effort to control the symptoms of a severe schizophrenia. Though she had been prescribed $75 \mathrm{mg}$ chlorpromazine three times daily, this regimen was followed irregularly, with occasions when the drug had been omitted completely, and others when the dose had been exceeded by a considerable but undetermined amount.

It is probable that one of the latter periods preceded her admission to a local hospital in October 1973, when she was complaining of vague epigastric pains, and also of fainting attacks, the latter never having been present before. After admission, the abdominal discomfort disappeared, but on two occasions she had a sudden loss of consciousness lasting two to three minutes, when she was observed to be pale and pulseless. Though after the first attack, clinical examination revealed no abnormality, an electrocardiogram recorded during the second episode showed a brief period of ventricular asystole, followed by a longer interval when complete heart block was present (Fig. I). Treatment was started with intravenous isoprenaline and Saventrine, and she was transferred to the Liverpool Regional Cardiac Centre for further observation.

She was withdrawn and submissive on admission, with no obvious physical abnormality on general ex- amination. There was no jaundice, no oedema, no signs of external injury, and she was not dyspnoeic at rest. Temperature was normal, pulse rate 140 a minute, brachial blood pressure $100 / 80 \mathrm{mmHg}$, and routine urine testing revealed both ketonuria and a moderate glycosuria.

Her plasma glucose was $240 \mathrm{mg} / 100 \mathrm{ml}$ on admission, but later became normal, I $7 \mathrm{mg} / \mathrm{r} 00 \mathrm{ml}$, taken I hour after a normal meal. An original hyponatraemia of 124 $\mathrm{mEq} / \mathrm{l}$. on admission, corrected spontaneously to 136 $\mathrm{mEq} / \mathrm{l}$. after 48 hours of normal diet. This was the only electrolyte abnormality shown, the serum potassium being normal throughout.

Arterial blood gas analysis was normal, but she had a moderate leucocytosis of $15,800 \mathrm{~mm}^{3}$. The serum bilirubin and alkaline phosphatase were normal, the oxaloacetic and pyruvic transaminases moderately raised.

Although her cardiac outline on the chest $x$-ray was normal, and her lung fields were clear, there was a summation gallop rhythm audible at the cardiac apex, but no murmurs. Her electrocardiogram at this stage showed sinus rhythm, with a PR interval of $0.21 \mathrm{sec}$, and both right bundle-branch block and left anterior hemiblock (Fig. 2).

All active treatment was withdrawn, and she was kept under continuous observation in the coronary monitoring unit. Shortly after admission an episode of ventricular tachycardia was stopped by the intravenous injection of a single bolus of $50 \mathrm{mg}$ lignocaine hydrochloride, and she remained in normal sinus rhythm for the next 24 hours.

Withdrawal of the chlorpromazine caused her to become noisy, restless, and aggressive. Haloperidol did not control the situation, and it became necessary to reintroduce the chlorpromazine. Given intravenously in divided doses totalling $300 \mathrm{mg}$ in 24 hours, her mental disturbance was controlled, but she now began to have supraventricular tachycardia, though complete heart block was not seen.

Sinus rhythm recurred spontaneously again after withdrawal of the chlorpromazine and the conduction defects disappeared. Her symptoms were controlled by 


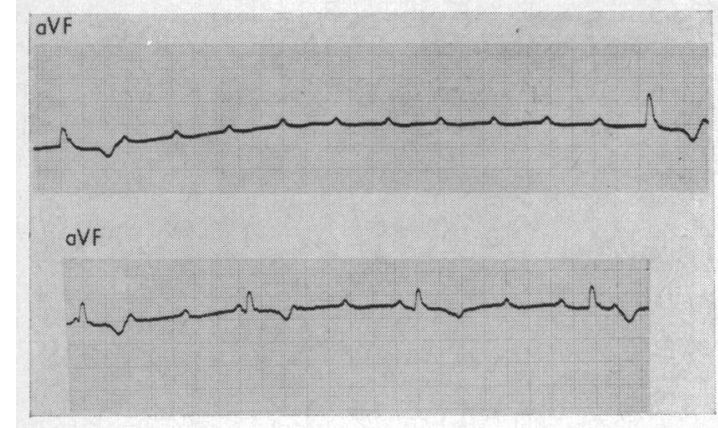

FIG. I Two strips (not continuous) of lead aVF recorded at the time of the second syncopal attack.

increased doses of haloperidol, and she was discharged from the coronary unit after 5 days, and has remained well since that date.

\section{Discussion}

Moyer and his co-workers (1954), reporting their clinical and experimental experience in the use of chlorpromazine, noted electrocardiographic changes including $T$ wave flattening, $Q R S$ spreading, and prolongation of the QT interval. They also mentioned the possible occurrence of Wenckebach periods, but the patient so affected had other possible causes for this phenomenon, i.e. diabetes and hypokalaemia.

Given in large doses to dogs, tachycardia and atrioventricular block were both seen, but in human control subjects no electrocardiographic changes were noted.

Dobkin, Gilbert, and Lamoureux (1954) showed that in healthy human subjects, after being given chlorpromazine, minor $\mathrm{T}$ wave abnormalities, and tachycardia when assuming an upright posture occurred. They also reported a patient suffering from severe frost-bite who was given $50 \mathrm{mg}$ chlorpromazine intravenously and seven intramuscular injections of $25 \mathrm{mg}$ at 6-hourly intervals, and who after a period of tachycardia developed first-degree heart block which lasted 'for a few days' before the electrocardiogram became normal. However, the electrocardiographic abnormality

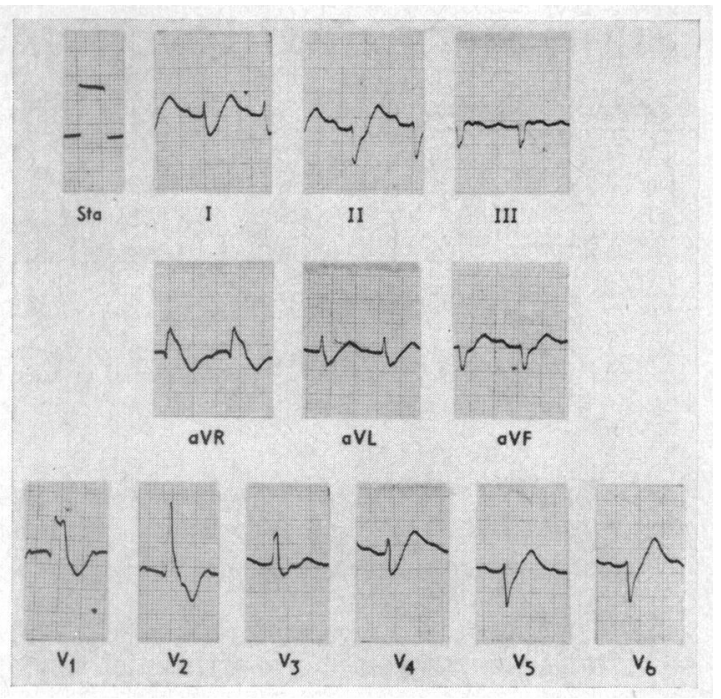

FIG. 2 Electrocardiogram recorded before the first withdrawal of chlorpromazine therapy, showing sinus rhythm, PR O.2I sec, right bundle-branch block, and left anterior hemibolck. These abnormalities later disappeared, leaving a normal record.

did not occur until after the last injection, and other factors may have been involved.

So far as we are aware, there has been no other report where both conduction defects and disturbances of cardiac rhythm have been related to the administration of chlorpromazine. In our patient withdrawal of the drug resulted in rapid recovery of normal rhythm without the necessity for other treatment.

\section{References}

Dobkin, A. B., Gilbert, R. G. B., and Lamoureux, L. (1954). Physiological effects of chlorpromazine. Anaesthesia, 9, I57.

Moyer, J. H., Kent, B., Knight, R., Morris, G., Huggins, R., and Handley, C. A. (1954). Laboratory and clinical observations on chlorpromazine (S.K.F.-260I-A) - hemodynamic and toxicological studies. American fournal of the Medical Sciences, 227, 283.

Requests for reprints to Dr. N. Coulshed, Liverpool Regional Cardiac Centre, Sefton General Hospital, Smithdown Road, Liverpool Lr5 $2 \mathrm{HE}$. 